\title{
МОДЕЛИРОВАНИЕ И ОЦЕНКА ЭФФЕКТОВ ИННОВАЦИОННОГО РАЗВИТИЯ ЭКСПОРТНОГО СЕКТОРА ЭКОНОМИКИ: ДАЛЬНИЙ ВОСТОК'
}

\begin{abstract}
Аннотация: Проводится сиенарное моделирование и оценка экономических эффектов от проведения мероприятий, которые, в соответствии с государственными программными документами, призваны способствовать инновачионному развитию экспортного сектора экономики Дальневосточного федерального округа, и, как следствие, нивелированию угроз для экономической безопасности макрорегиона, обусловленных его экспортными трансакцииями. В качестве исходных посылок исследуемых сиенариев рассматриваются: развитие экспортной специализации округа на продукции обрабатывающих производств; изменение параметров технологического развития экспортного сектора макрорегиона. В рамках первого сиенария выявлены производства, экспорт продукиии которых обеспечит генерацию максимальных приростов валового регионального продукта округа, а также указаны ограничения для получения соизмеримых эффектов при развитии других специализированных производств Дальневосточной экономики. В рамках второго сценария идентифицированы факторы инновационного развития экспортного сектора, снижающие риски технологической зависимости экономики Дальневосточного федерального округа от других государств, генерируемые импортом машин и оборудования.

Review: The article contains scenario modeling and evaluation of economic effects from the events aimed for innovative development of the economy of the Far Eastern Federal District and for neutralization of export-transaction related threats to the economic security of the macro-region according with the state programs. The author uses the following prerequisites for the evaluated scenarios: development of export specialization of the district in the sphere of manufacturing activity; changes in the parameters for the technical development of the export sector of the macro-region. Within the first scenario the author singles out export of manufacturing products, which shall generate maximal growth of the gross regional product for the district, as well as limitations for the comparable effects in case of development of other specialized manufactures of the Far Eastern economics. Within the second scenario the author identifies the factors for the innovative development of the export sector, lowering the risks of technological dependency of the Far Eastern Federal District on the other states, which is generated by import of equipment and machinery.
\end{abstract}

Ключевые слова: экспортный сектор экономики, сырьевой экспорт, инновационное развитие, экономическая безопасность, экономический эффект, экспортная специализация, техническое перевооружение производств, технологическая зависимость, макрорегион, Дальневосточный федеральный округ

Keywords: export sector of economy, raw products export, innovative development, economic security, economic effect, export specialization, technical, manufacturing re-equipment, macro-region, Far Eastern Federal District

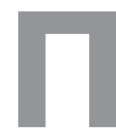

ереход к инновационному развитию экономики включен в круг первоочередных задач, определенных для РФ в государственных программных документах ${ }^{2}$. Необходимость

\footnotetext{
${ }^{1}$ Подготовлено при поддержке грантов РФФИ 12-06-31110, ДВО РАН 12-II-УО-10-019.

${ }^{2}$ Концепция долгосрочного социально-экономического развития РФ на период до 2020 г. (Распоряжение Правительства РФ от 17.11.2008 N 1662-р); Стратегия инновационного развития России на период до 2020 г. (Распоряжение Правительства РФ от 08.12.2011 N 2227-p.) и др.
}

осуществления такого перехода не вызывает сомнений: анализ современных тенденций развития мировой и российской экономики позволяет идентифицировать как внешние (ускорение технологического развития; усиление борьбы государств за факторы конкурентоспособности экономики (к примеру, высококвалифицированную рабочую силу); нестабильность конъюнктуры мирового рынка и т.д.), так и внутренние (низкая степень диверсификации экономики; зависимость от сырьевого сектора и т.д.) вызовы для экономической безопасности последней. Уменьшение «чувстви- 
тельности» национальной экономики к экзогенным шокам, снижение эндогенных ограничений для её роста связываются с проведением мероприятий, способствующих инновационному развитию экономики. Проблема, тем не менее, заключается не в том, чтобы сформировать перечень соответствующих мероприятий (его содержание определено разработчиками государственных программ), а в том, что независимость экономического и инновационного блоков в программных документах не позволяет рассматривать изменения в первом блоке как функцию от реализации мероприятий из второго блока и, стало быть, количественно оценить влияние последних на результаты экономической деятельности. Между тем, потребность в проведении подобных исследований имеет довольно высока и обуславливается отнюдь не стремлением доказать или опровергнуть целесообразность программных «алгоритмов» развития (которая в данном случае принимается за аксиому). Научный интерес заключается в получении знания о потенциальных эффектах, которые при этом может получить экономика; определении условий максимизации экономических «выигрышей»; идентификации ограничений для инновационного развития экономики и отдельных элементов ее структуры.

Исходные данные и методические аспекты исследования. Особенности структуры экономики, неравенство объемов и качества факторов производства, различия природно-географических условий не могут гарантировать единства в «реакциях» различных регионов на проведение инновационных мероприятий. Получение прогнозных оценок в целом по стране не позволит учесть возможные диспропорции в изменениях региональных показателей и, как следствие, сформировать точные сценарии инновационного развития экономики страны в территориальном разрезе. Данное обстоятельство требует трансформации формального представления последней: а именно отказа от ассоциаций с некой «точкой», лишенной внутреннего пространства. Одним из оснований для учета пространственного фактора при описании национальной экономики может являться административно-территориальное деление страны: в случае РФ единицами анализа выступят федеральные округа, республики, края, области, автономные округа, автономная область, муниципальные образования. Помимо территориального разреза, повышению качества исследования и оценки эффектов инновационного развития национальной экономики будет способствовать ее секторальная детализация.

В нашем случае объектом исследования является экспортный сектор экономики Дальневосточного федерального округа (ДФО) РФ, образованный совокупностью производств, продукция которых составляет основную массу экспорта макрорегиона.

Выбор объекта исследования не является случайным. Начиная с 1990-х гг. и по настоящее время экспорт выступает важным фактором и условием развития Дальневосточной экономики: значение экспортной квоты в промышленности в 2007 г. - 46,9\%, 2011 г. - 48\%; удельный вес промышленности в структуре экономики ДФО 2007 г. - 32,4\%, 2011 г. - 36,3\% ${ }^{3}$.

Агрегация таможенной статистики экспортных потоков, представленной по отдельным товарным позициям, в товарные группы (в соответствии с Общероссийским классификатором видов экономической деятельности) позволяет идентифицировать производства, продукция которых преобладает в структуре экспорта Дальневосточного макрорегиона: добыча топливно-энергетических полезных ископаемых, лесозаготовки, рыболовство, производство пищевых товаров, включая напитки, и табака 4 .

Анализ государственных программных документов показывает, что инновационное развитие экспортного сектора Дальневосточной экономики связывается с преодолением доминирования ресурсной составляющей в структуре поставок макрорегиона на мировой рынок ${ }^{5}$ (так, доля нефти в экспорте продукции ТЭК, занимающей 55,2\% совокупного экспорта округа, в 2008 г. составила $88,4 \%$; угля $\left.-7,6 \%^{6}\right)$.

\footnotetext{
${ }^{3}$ Рассчитано на основе материалов официального сайта Федеральной службы государственной статистики. [Электронный pecypc] // URL: http://www.gks.ru.

${ }^{4}$ Белоусова А.В., Потанин М.М., Колесникова А.Ю. Экспортный сектор экономики Дальнего Востока: вектор инновационного развития // Национальная безопасность. 2012. №6 (23). С. 44-54.

${ }^{5}$ Белоусова А.В. Условия и параметры инновационного развития экспортного сектора экономики Дальнего Востока: анализ стратегических приоритетов // Экономика, управление, общество: история и современность: материалы XI Всероссийской научно-практической конференции молодых исследователей, магистрантов и аспирантов. Ч. 1. - Хабаровск: ДВИ-филиал РАНХиГС, 2013. С. 44-47.

${ }^{6}$ Белоусова А.В., Потанин М.М., Колесникова А.Ю. Экспортный сектор экономики Дальнего Востока: вектор инновационного развития // Национальная безопасность. 2012. №6 (23). С. 44-54.
} 
Риски для устойчивого роста и развития ресурсозависимой экономики (ресурсы составляют не менее $40 \%$ экспорта), описываемые в научной литературе, заключаются в: невысоком потенциале экспортного сектора, связанном с ограниченностью запасов ресурсов (включая возобновляемые); низкой трудоёмкости ресурсных производств, которая при расширении масштабов первичного сектора, способствует увеличению уровня безработицы; ограниченности возможностей экономики для гибкого реагирования на изменение конъюнктуры внешнего рынка и т.д. ${ }^{7}$ Помимо научных исследований, негативные последствия зависимости экономики от экспорта ресурсов подтверждаются эмпирической динамикой экономических показателей: так, в период мирового кризиса сокращение экспортного спроса в IV квартале 2008 г. по отношению к соответствующему периоду 2007 г. на $35,4 \%$ обусловило спад основных индикаторов экономики ДФО (индекс промышленного производства в целом за год составил 99,8\%, добычи полезных ископаемых $-98,4 \%)^{8}$.

В числе мероприятий, предлагаемых в государственных программных документах для перехода экспортного сектора экономики ДФО на путь инновационного развития, отмечаются: 1) развитие специализации макрорегиона в международном разделении труда на продукции обрабатывающих производств (увеличение глубины переработки экспортируемого сырья; рост доли конечной продукции в структуре экспорта (в т.ч. высокотехнологичной); 2) модернизация и техническое перевооружение производств сектора ${ }^{9}$. Данные мероприятия рассматриваются в качестве исходных посылок в исследуемых автором сценариях инновационного развития экспортного сектора Дальневосточной экономики.

В качестве инструментария, на базе которого были получены количественные оценки эффектов иннова-

\footnotetext{
${ }^{7}$ Белоусова А.В. Региональный вывоз в экономике Хабаровского края: шоки и эффекты. Хабаровск: КГУП «Хабаровская краевая типография». 2011. 128 с.

${ }^{8}$ Рассчитано на основе материалов официального сайта Федеральной службы государственной статистики. [Электронный peсурc] // URL: http://www.gks.ru.

${ }^{9}$ Белоусова А.B. Условия и параметры инновационного развития экспортного сектора экономики Дальнего Востока: анализ стратегических приоритетов // Экономика, управление, общество: история и современность: материалы XI Всероссийской научно-практической конференции молодых исследователей, магистрантов и аспирантов. Ч. 1. - Хабаровск: ДВИ-филиал РАНХиГС, 2013. С. 44-47.
}

ционного развития экспортного сектора, использовалось эконометрическое моделирование. Поскольку количество точек наблюдения ограничивалось коротким временным интервалом (сценарий 1 - 11 лет (2000-2010 гг.); сценарий 2 - 6 лет (2005-2010 гг.), что делало невозможным получение статистически надежных оценок, увеличение объема исходной информации происходило за счет ее организации в панельную структуру (использовались данные по субъектам РФ, входящих в состав ДФО). Расчеты производились в сопоставимых ценах; в качестве базового был принят 2007 год.

Результаты исследования. Сиенарий 1. Развитие экспортной специализачии ДФО на продукции обрабатывающих производств. Анализ базового сценария развития экономики ДФО в «Стратегии социально-экономического развития Дальнего Востока и Байкальского региона на период до 2025 г.» ${ }^{10}$, увязанного с инновационным сценарием «Концепции долгосрочного социально-экономического развития РФ на период до 2020 г.» ${ }^{11}$, позволяет идентифицировать производства, которые составят экспортный сектор Дальневосточной экономики при его инновационном развитии. Так, увеличение степени переработки добываемых ресурсов обусловит непременное включение в экспортный сектор производства кокса и нефтепродуктов и обработки древесины и производства изделий из дерева. Производство продовольственных товаров, включая напитки, и табака, по-прежнему, останется в составе экспортного сектора, поскольку данный вид деятельности включает как первичные стадии обработки рыбы, ракообразных и моллюсков - охлаждение и заморозку, так и стадии более глубокой обработки к примеру, консервирование, производство готовых рыбных блюд. Развитие высокотехнологичных производств, в первую очередь, авиа- и судостроения, обусловит включение в состав экспортного сектора такого вида экономической деятельности как производство транспортных средств и оборудования.

Применение методов эконометрического моделирования позволило провести количественный анализ зависимостей валового регионального продукта (ВРП) от экспорта ДФО, представленного в

\footnotetext{
${ }^{10}$ Стратегия социально-экономического развития Дальнего Востока и Байкальского региона на период до 2025 г. (Распоряжение Правительства РФ от 28 декабря 2009 г. № 2094-р.).

${ }^{11}$ Концепция долгосрочного социально-экономического развития РФ на период до 2020 г. (Распоряжение Правительства РФ от 17.11.2008 N 1662-p).
} 


\section{Национальная безопасность 4(27) • 2013}

разрезе товарных групп. Входные данные оцениваемых моделей формировались исходя из следующих предпосылок: 1) инерционное развитие экспортного сектора: сектор сохраняет состав, сложившийся на протяжении 2000-2010 гг.; экономика округа продолжает характеризоваться ресурсной специализацией; 2) инновационное развитие экспортного сектора: в состав сектора включаются производства, отмеченные выше ${ }^{12}$; экономика округа специализируется на продукции обрабатывающих производств (табл. 1). товаров, как уже было отмечено выше, объясняются превалированием в поставках на мировой рынок продукции с более низкой добавленной стоимостью (охлажденной и замороженной рыбы). В случае экспорта продукции ТЭК полученные оценки связываются с особенностями таможенного оформления поставок ${ }^{13}$.

Сценарий 2. Изменение параметров технологического развития производств экспортного сектора экономики ДФО. Согласно «Стратегии социально-экономического развития Дальнего Востока и Байкальского

Таблииа 1

Соотношение изменений экспорта и ВРП ДФО

\begin{tabular}{|l|c|c|c|c|c|}
\hline $\begin{array}{c}\text { Экспортный сектор } \\
\text { экономики ДФО / } \\
\text { прирост ВРП ДФО, } \\
\text { обеспечиваемый } \\
\text { экспортом }\end{array}$ & $\begin{array}{c}\text { Продовольст- } \\
\text { венные товары } \\
\text { и с/х сырье, } \\
\text { тыс. руб. }\end{array}$ & $\begin{array}{c}\text { Продукция } \\
\text { ТЭК, } \\
\text { тыс. руб. }\end{array}$ & $\begin{array}{c}\text { Древесина } \\
\text { и изделия из } \\
\text { неё, } \\
\text { тыс. руб. }\end{array}$ & $\begin{array}{c}\text { С, } \\
\text { тыс. руб. }\end{array}$ & $\mathrm{R}^{2}$ \\
\hline Инерционное развитие & $\begin{array}{c}6,7 \\
(3,7)\end{array}$ & $\begin{array}{c}1,2 \\
(7,7)\end{array}$ & $\begin{array}{c}17,6 \\
(6,2)\end{array}$ & $\begin{array}{c}30211125 \\
(3,5)\end{array}$ & 0,79 \\
\hline $\begin{array}{l}\text { Инновационное } \\
\text { развитие }\end{array}$ & $\begin{array}{c}2,9 \\
(4,8)\end{array}$ & $\begin{array}{c}52,1 \\
(3,8)\end{array}$ & $\begin{array}{c}44227479 \\
(12,4)\end{array}$ & 0,92 \\
\hline
\end{tabular}

Прилечания: 1) При инерционном развитии экспортный сектор экономики ДФО образуют следующие производства: добыча топливно-энергетических полезных ископаемых; лесозаготовки; рыболовство; производство пищевых продуктов, включая напитки, и табака; при инновационном развитии - производство кокса и нефтепродуктов; обработка древесины и производство изделий из дерева; производство пищевых продуктов, включая напитки, и табака; 2) В скобках приведены значения t-статистик; 3) Стоимостное изменение экспорта каждой товарной группы во всех случаях составит 1 тыс. руб.; 4) C- свободный член; 5) $\mathrm{R}^{2}$ - коэффициент детерминации.

Источник: расчеты автора

Согласно проведенным расчетам, включение обрабатывающих производств в экспортный сектор обеспечит сравнительно большие эффекты для экономики ДФО, нежели сохранение существующего состава сектора. Так, исходя из полученных оценок, прирост к примеру, экспорта древесины и изделий из нее на 1 тыс. руб. в современных условиях обеспечивает стоимостное изменение ВРП ДФО на 17,6 тыс. руб.; между тем, развитие деревообрабатывающих производств в экспортном секторе макрорегиона и прирост экспорта продукции деревообработки на 1 тыс. руб. позволит получить прирост ВРП ДФО в 52,1 тыс. руб.

Сравнительно более низкие приросты ВРП ДФО, генерируемые экспортом продовольственных

${ }^{12} \mathrm{C}$ целью обеспечения сопоставимости получаемых результатов, во втором случае производство транспортных средств было выведено за пределы исследования

региона на период до 2025 г.», в качестве ключевого фактора модернизации и технического перевооружения производств в экономике ДФО, и в частности, в ее экспортном секторе, рассматривается импорт машин и оборудования. Стимулами для покупки оборудования в других странах должно стать использование инструментов таможенной и налоговой политики, а именно, снижение импортных пошлин и частичное субсидирование приобретения отдельных видов оборудования ${ }^{14}$.

Применение методов эконометрического моделирования на основе панельных данных позволило оценить эластичность выпуска продукции иннова-

\footnotetext{
${ }^{13}$ Белоусова А.В. Региональный вывоз в экономике Хабаровского края: шоки и эффекты. Хабаровск: КГУП «Хабаровская краевая типография», 2011. 128 с.

${ }^{14}$ Стратегия социально-экономического развития Дальнего Востока и Байкальского региона на период до 2025 г. (Распоряжение Правительства РФ от 28 декабря 2009 г. № 2094-р.).
} 
ционного экспортного сектора экономики ДФО от импорта машин и оборудования (табл. 2). факторов рассматриваются затраты на технологические новации. Данный показатель предполагает следующие

Таблииа 2 Коэффициенты эластичности выпуска продукичи инновационного экспортного сектора экономики ДФО по импорту машин и оборудования

\begin{tabular}{|l|c|c|c|}
\hline & $\begin{array}{c}\text { Импорт машин и } \\
\text { оборудования }\end{array}$ & $\mathrm{C}$ & $\mathrm{R}^{2}$ \\
\hline $\begin{array}{l}\text { Выпуск продукции } \\
\text { экспортного сектора }\end{array}$ & $\begin{array}{c}0,35 \\
(8,65)\end{array}$ & $\begin{array}{c}6,3 \\
(17,33)\end{array}$ & 0,91 \\
\hline
\end{tabular}

Источник: расчеты автора

Установлено, что наращивание объемов закупок машин и оборудования за рубежом будет генерировать положительный эффект для выпуска продукции экспортного сектора: увеличение импорта на $1 \%$ повлечет увеличение выпуска инновационной продукции на $0,35 \%$.

Между тем, согласно мнению большинства ученых и специалистов, ставка на импорт машин и оборудования как на основной фактор модернизации и технического перевооружения производств в экономике, создает угрозу технологической зависимости последней от других государств. Последнее обстоятельство является прямой угрозой для экономической безопасности макрорегиона. Приобретение требуемого оборудования за рубежом лишает заказов отечественный научно-производственный сектор; снижает спрос на человеческий капитал в секторе, ориентированном на внутренний спрос; не создает предпосылок для развития внутренних цепочек добавленной стоимости, которые отвечали бы требованиям к современной наукоемкой продукции ${ }^{15}$. В связи с этим, возникает проблема выявления альтернативных факторов технологического «апгрейда» экспортного сектора экономики ДФО. В настоящем исследовании в качестве одного из таких статьи расходов: затраты на исследования и разработки, приобретение машин и оборудования, обучение и подготовка персонала, связанная с инновациями, маркетинговые исследования и т.д.

Отсутствие знания о структуре затрат на технологические новации по всем субъектам РФ, входящим в состав ДФО, обусловило необходимость использования методов корреляционного анализа. Поскольку, как было отмечено выше, затраты на технологические новации могут направляться на приобретение машин и оборудования, проверялась гипотеза о присутствии высокой степени корреляции между затратами на технологические новации и импортом машин и оборудования. Впоследствии данная гипотеза была отвергнута: значение коэффициента корреляции составило всего лишь 0,1.

Проведенные расчеты показали, что $1 \%$-ный прирост затрат на технологические новации продуцирует меньший (в сравнении с импортом машин и оборудования) стоимостной прирост выпуска продукции экспортного сектора экономики ДФО. При этом данный эффект статистически оценивается, начиная с года, следующего за тем, в котором были осуществлены затраты (табл. 3).

Таблица 3 Коэффициенты эластичности выпуска продукиии инновационного экспортного сектора экономики ДФО по затратам на технологические новации

\begin{tabular}{|c|c|c|c|}
\hline & $\begin{array}{c}\text { Затраты на технологические } \\
\text { новации, осуществленные } \\
\text { годом ранее }\end{array}$ & $\mathrm{C}$ & $\mathrm{R}^{2}$ \\
\hline Выпуск продукции экспортного сектора & $\begin{array}{c}0,19 \\
(3,58)\end{array}$ & $\begin{array}{c}8,3 \\
(13,58)\end{array}$ & 0,93 \\
\hline
\end{tabular}

${ }^{15}$ Карачаровский В. Инновационные процессы: национальный Источник: расчеты автора и региональный разрез // Экономист. 2012. №10. С. 23-35. 
На первый взгляд, полученные оценки обосновывают выбор импорта машин и оборудования в качестве основного фактора роста выпуска инновационной продукции экспортного сектора ДФО. Между тем, необходимо отметить, что $1 \%$-ное изменение стоимости импорта машин и оборудования соответствует 33,5\%-ному изменению величины затрат на технологические новации. В связи с этим, в случае отказа от импорта машин и оборудования в текущем году и пропорционального увеличения объема затрат на технологические новации стоимостной прирост выпуска в последующем году, при прочих равных условиях, должен составить $6 \%$.

$* * *$

Таким образом, количественный анализ мероприятий, способствующих, согласно государственным программным документам, инновационному развитию экспортного сектора экономики ДФО, позволил сделать следующие выводы. В случае развития специализации Дальнего Востока на продукции обрабатывающих производств, максимальный экономический эффект, в виде прироста ВРП макрорегиона, будет обеспечивать экспорт древесины и изделий из нее. Возможными причинами получения сравнительно меньших эффектов от экспорта продовольственных и топливно-энергетических товаров являются первичные стадии их обработки и особенности таможенного оформления поставок на международный рынок соответственно. Импорт машин и оборудования обеспечит генерацию эффекта для экономики ДФО, в виде увеличения выпуска инновационной продукции ее экспортного сектора, в более короткие сроки, нежели осуществление затрат на технологические новации. Однако, более детальный анализ позволил выяснить, что соизмеримая замена стоимости импорта машин и оборудования затратами на технологические новации, с учетом преодоления временного лага и при прочих равных условиях, позволит получить «выигрыш» для прироста выпуска инновационной продукции экспортного сектора ДФО более, чем в 5 п.п. При этом барьерами для осуществления вышеназванной замены выступают: несовпадение «источников финансирования»; стремление к получению «быстрой отдачи» от вложений; угроза потери части прогнозируемых эффектов в силу возможных изменений параметров развития экономики на более длинном временном интервале и т.д. В данном контексте, затраты на технологические новации могут рассматриваться в качестве дополнительного фактора инновационного развития экспортного сектора ДФО в среднесрочной перспективе и основного фактора - в случае вынужденного сокращения импорта машин и оборудования макрорегиона.

\section{Библиография:}

1. Белоусова А.В. Региональный вывоз в экономике Хабаровского края: шоки и эффекты. Хабаровск: КГУП «Хабаровская краевая типография», 2011. 128 с.

2. Белоусова А.В. Условия и параметры инновационного развития экспортного сектора экономики Дальнего Востока: анализ стратегических приоритетов // Экономика, управление, общество: история и современность: материалы XI Всероссийской научно-практической конференции молодых исследователей, магистрантов и аспирантов. Ч. 1. - Хабаровск: ДВИ-филиал РАНХиГС, 2013. С. 44-47.

3. Белоусова А.В., Потанин М.М., Колесникова А.Ю. Экспортный сектор экономики Дальнего Востока: вектор инновационного развития // Национальная безопасность. 2012. №6 (23). C. 44-54.

4. Карачаровский В. Инновационные процессы: национальный и региональный разрез // Экономист. 2012. №10. С. 23-35.

5. Концепция долгосрочного социально-экономического развития РФ на период до 2020 г. (Распоряжение Правительства РФ от 17.11.2008 N 1662-p).

6. Сайт Федеральной службы государственной статистики. [Электронный ресурс] // URL: http://www.gks.ru

7. Стратегия инновационного развития России на период до 2020 г. (Распоряжение Правительства РФ от 08.12.2011 N 2227-p.).

8. Стратегия социально-экономического развития Дальнего Востока и Байкальского региона на период до 2025 г. (Распоряжение Правительства РФ от 28 декабря 2009 г. № 2094-р.).

\section{References (transliteration):}

1. Belousova A.V. Regional'nyy vyvoz v ekonomike Habarovskogo kraya: shoki i effekty. Habarovsk: KGUP «Habarovskaya kraevaya tipografiya», 2011. 128 s. 
DOI: $10.7256 / 2073-8560.2013 .4 .8957$

При цитировании этой статьи сноска на dоі обязательна

Технологии и методология в системах безопасности

2. Belousova A.V. Usloviya i parametry innovacionnogo razvitiya eksportnogo sektora ekonomiki Dal'nego Vostoka: analiz strategicheskih prioritetov // Ekonomika, upravlenie, obschestvo: istoriya i sovremennost': materialy XI Vserossiyskoy nauchno-prakticheskoy konferencii molodyh issledovateley, magistrantov i aspirantov. Ch. 1. - Habarovsk: DVI-filial RANHiGS, 2013. S. 44-47.
3. Belousova A.V., Potanin M.M., Kolesnikova A.Yu. Eksportnyy sektor ekonomiki Dal'nego Vostoka: vektor innovacionnogo razvitiya // Nacional'naya bezopasnost'. 2012. №6 (23). S. 44-54.

4. Karacharovskiy V. Innovacionnye processy: nacional'nyy i regional'nyy razrez // Ekonomist. 2012. №10. S. 23-35. 